\title{
La qual çibdad: las relativas con antecedente adjunto del siglo XIII a hoy. Evolución de un procedimiento cohesivo*
}

\section{Por Lola Pons Rodríguez}

1. Si bien a un pronombre relativo como el cual se le supone la capacidad inherente de introducir subordinación, nos encontramos, con notabilísima frecuencia en la lengua antigua, a este pronombre relativo encabezando oraciones que no podrían calificarse de subordinadas sino de yuxtapuestas ${ }^{1}$; en ellas, el cual encabeza un enunciado independiente, aunque remitiendo a un antecedente contenido en el decurso anterior. Esta clase de oraciones funciona en español actual en condiciones contextuales muy restringidas: el antecedente del relativo ha de figurar al final del enunciado precedente; además, el relativo aparece encabezando la oración, al final de sintagma preposicional (El acusado colaboró en la resolución del caso, gracias a lo cual se pudo dictar sentencia) o tras participio, como sujeto de cláusula absoluta (Cumplimentamos la solicitud, hecho lo cual, ya estaba todo más cerca de terminar). Otras condiciones, sin ser de estricta aparición, parecen favorecer el uso de estos giros de relativo yuxtapuestos: cuando el relativo está encabezando el enunciado y tiene antecedente no oracional presenta, por lo general, carácter de inciso que aporta una información complementaria, lateral, con aplicación conclusiva²; con todo, son más comunes los antecedentes oracionales y el uso, por tanto, de lo cual.

En la lengua antigua, en cambio, el funcionamiento de estas estructuras es divergente al de hoy, pues no parecen operar todas estas condiciones de funcionamiento: por ejemplo, el antecedente del relativo no figura siempre al final del enunciado precedente. Por otro lado, la construcción yuxtapuesta que encabeza el cual no se utiliza sólo para presentar contenidos digresivos que aparten a la oración que sigue del tópico principal del discurso. Hoy el cual puede introducir información con grado de pertinencia diverso, pero nunca abre la introducción de un punto de partida para un tema nuevo. En la lengua medieval, en cambio, esas estructuras con $e$ cual pueden abrir un periodo nuevo con comentarios inéditos sobre el tema del discurso, dan información nueva y desempeñan un papel fundamental en el avance de la progresión temática. En algunos casos se hallan valores conclusivos en el relativo, pero no parece ser esa la función en que éste está especializado.

Otra característica que ha cambiado del castellano antiguo a hoy es el grado de frecuencia de el cual en yuxtapuestas con antecedente adjunto,

\footnotetext{
* Agradezco a Manuel Ariza Viguera su atenta lectura de este trabajo; tengo en cuenta sus generosas aportaciones al original.
} 
estructuras que me ocuparán en este trabajo. En esos casos el relativo se une a un núcleo nominal que reproduce al antecedente del relativo o remite a él:

(1a) E oyó misa el Rey, e ellos aparte, la qual misa dio el obispo de León (Pero Carrillo de Huete, Crónica del halconero, 66) 3 .

El cual procede, como es sabido, de QUALIS, adjetivo latino interrogativo o relativo, en correlación con TALIS (cfr. Elvira 1985 para más datos del surgimiento de el cual desde QUALIS). La incorporación de antecedente (o de un sinónimo del antecedente), impracticable con QUALIS, sí era posible con el pronombre relativo QUIS, QUAE, QUOD, sobre todo en la lengua arcaica y algo menos, en la clásica:

(2) erant omnino duo itinera quibus itineribus domo exire possent (César).

Cuervo (s. v. cual) calificaba este uso de "giro puramente latino"; el Esbozo (1973: 2.7.5.c) afirma que en tales casos el cual "funciona [...] como relativo adjetivo". Fernández Ramírez (1987: 239 n. 651) no trata de esta configuración con antecedente, aunque sí la menciona („,consiste en agrupar el sustantivo con el relativo el cual como término secundario"). Las descripciones que se hacen actualmente de la extensión de este esquema con antecedente incluido inciden en su carácter residual y marcado. Para el Diccionario panhispánico de dudas (2005, s. v. cual 2.2.) es una construcción (que llama de „adjetivo relativo antepuesto a un sustantivo") hoy infrecuente, por ser sustituida por relativo pospuesto: ciudad en la cual, fin que no fue otro [...]. Por su parte, Gómez Torrego (2002: 5.1.12) liga su uso a un deseo de esclarecimiento del antecedente (Me trajeron la medalla en una bandeja, la cual bandeja era de plata), pero afirma que es una construcción „poco natural”; Herrero (2005: 157) otorga a este uso „carácter marcadamente retórico o estilístico".

Efectivamente, hoy en una oración como la de (1) encontraríamos otra forma de remisión al sustantivo misa: un demostrativo (esa misa), o, muy posiblemente una "relativa con antecedente reasuntivo yuxtapuesto" (Brucart 1999: 243):

(1b) Oyó el Rey misa, misa que dio el obispo de León.

(1a) y (1b) nos presentan, pues, dos mecanismos de cohesión distintos basados en un mismo proceso de correferencia entre argumentos nominales. Un aspecto interesante de construcciones como las de (1a), y que tiene consecuencias de relevancia para la teoría sobre la cohesión (Esparza Torres 2006), es el hecho de que el procedimiento que aquí describo hace saltar la separación entre cohesión por referencia y cohesión léxica ${ }^{4}$ Si un relativo como el cual funciona como 
mecanismo de cohesión referencial, la repetición de un sustantivo -o su evocación mediante una nueva entidad nominal que lo apela - implica, desde luego, un procedimiento de cohesión léxica. Cohesión léxica y referencial se unen, pues, en un empleo donde el relativo deja de funcionar como pronombre para pasar a ser un determinante.

2. Con estos antecedentes, indagaré en las propiedades formales y discursivas que a lo largo del decurso diacrónico muestra el uso de cual con antecedente adjunto como procedimiento de cohesión. Este artículo se quiere adscribir a una línea de trabajo sobre la evolución de la organización informativa del discurso diacrónico (vid. Pons Rodríguez 2001-2002; 2006a entre otros). Ciertamente, el análisis evolutivo de los recursos cohesivos en español ha merecido gran interés en los estudios de construcción discursiva en diacronía, especialmente privilegiando el examen de la dimensión de los conectores. Menor ha sido la atención dedicada a la progresión informativa (pueden verse para esto los trabajos de Borreguero / Octavio de Toledo 2006) Otra dimensión que merece estudio es la de los recursos de cohesión manifiestos en planos como las redes anafóricas y léxicas o la actuación de la elipsis. En este plano podemos ubicar trabajos como los de Barra Jover (2007 y 2008) y Girón Alconchel (2003), no demasiados si consideramos la importancia de esta clase de redes y la importante evolución que han sufrido a lo largo de la historia del español.

Para obtener datos sobre el asunto estudiado, se ha constituido un corpus cuantitativamente extenso, formado por más de sesenta obras de las que prácticamente todas - sólo dos se exceptúan- se han despojado de forma completa. A su vez, la extensión de las obras es media o larga ${ }^{5}$. Es un corpus extenso también desde el punto de vista de la cronología, pues abarca desde el siglo XIII al XIX; se ha querido en él ampliar por la derecha el arco temporal tradicionalmente manejado como base en los estudios de historia de la lengua española. Esta decisión se toma con objeto de, por un lado, romper el tradicional cierre de los estudios de diacronía en el siglo XVII, dando por hecho que el español dieciochesco es español moderno y coincide en sus rasgos con el español moderno de hoy; por otro lado, se hacía necesario acudir a ese lapso dormido hasta ahora en los estudios de diacronía a la búsqueda de los porqués de numerosos cambios que tuvieron lugar en la estructuración discursiva y la construcción textual durante los siglos XVIII y XIX. Tal vez influyera en tales cambios la aparición en escena de nuevos tipos de texto, nuevas tradiciones discursivas $^{6}$ en las que se exploraron mecanismos diversos de elaboración lingüística: la nueva lengua del periodismo, el nuevo ensayismo, los proyectistas, etc. Como se observará, no ha habido total equilibrio en el reparto cronológico de las obras estudiadas, pues se ha aumentado el número de obras despojadas en aquellas centurias en que, por intuiciones basadas en algunas calas previas, parecían ocurrir quiebres interesantes en la evolución de la estructura. 
Por último, se ha buscado conformar un corpus plural en cuanto a las tradiciones discursivas que se estudian. Por ello, se ha tratado de representar evolutivamente la historia de algunas de ellas intentando apreciar si en el desarrollo de la configuración objeto de análisis puede describirse una sola línea de cambio o si convivieron varias en paralelo. En el corpus figuran, entre otros, textos notariales y jurídicos (Siete Partidas, Colección documental del Monasterio de santa María de Carbajal, Colección documental del Monasterio de san Esteban de Nogales, Documentos inéditos para la historia de España, Inventario y tasación de los bienes de Fernando de Valenzuela); textos historiográficos (el Paso honroso de Suero de Quiñones, la Crónica del Halconero de Juan II, De la guerra de Granada, Conquista de las islas Malucas, Historia de la conquista y población de la provincia de Venezuela); relacionados con los anteriores, se introducen libros de viajes (la Embajada a Tamorlán de González de Clavijo, el Viaje del mundo de Ordóñez de Ceballos, el Viaje a Italia de Moratín); otra dirección discursiva que se ha incluido corresponde a los tratados expositivos (los Castigos del rey don Sancho, el Arte cisoria de Villena, el Tratado de la perfección del triunfo militar de Palencia, el Tratado de re militari de Salazar, misceláneas como el Jardín de flores curiosas de Torquemada o la Silva de varia lección de Pero Mexía); hay también prosa de ficción: novela sentimental, picaresca, novela realista, de costumbres, diálogo celestinesco...

3. El corpus investigado se ha mostrado bastante productivo en la documentación de esta estructura; cuarenta y tres de las obras escrutadas han ofrecido ejemplos, que, una vez estudiados, permiten esbozar una aproximación a sus propiedades de comportamiento sintáctico-formal.

En cuanto al reparto del relativo por género y número, se observa un mayor uso (más del doble) en singular que en plural; la variación genérica tiene menor interés, salvo en una cuestión: la casi nula incidencia del neutro lo cual, que se combina sólo con el cuantificador de universalidad todo y que, como se verá, está en desventaja con respecto a su competidor en gran parte del periodo estudiado: la(s) cual(es) cosa(s). Los datos porcentuales de distribución de formas relativas con antecedente adjunto separadas por género y número son estos:

$\begin{array}{lll} & \text { Singular } & \text { Plural } \\ \text { Masculino } & 38,2 \% & 11,6 \% \\ \text { Femenino } & 33 \% & 16,7 \% \\ \text { Neutro } & 0,4 \% & \end{array}$

Con respecto al papel sintáctico, cual con antecedente aparece desempeñando muy diversas funciones en la oración que encabeza (sujeto, objeto directo e indirecto, circunstancial, complemento del nombre y del adjetivo, etc.): 
(2) Con mandado del iuez vende tal casa o tal heredad en nonbre del huerfano que tiene en guarda atal onbre resçibiente por si \& por sus herederos por iuro de heredad por sienpre iamas la qual casa es en tal lugar \& ha tales linderos (7PAR: $3^{a}$ partida).

(3) Tenga esta arqueta su cerradura e la llave el cortador traiga consigo. La qual arqueta traer deve un omne ant'él, de guisa que la vea, al palacio a la ora del comer (CISO: 157).

(4) E estavan allí todas las altas duennas de la tierra e avn otras de muy lexos tierra, entre las quales duennas estaua la muy fermosa Elena (LEO: 166).

(5) E a todos sean manifiesto que allí estarán presentes dos cavalleros antiguos provados en armas e dignos de fee, e dos farautes, a los quales cavalleros $e$ gentileshomes que allí a fazer armas vernán, farán juramento (PASO: 94).

(6) dixo que se contenía en vn capítulo de çiertas seguridades, firmadas e selladas del nonbre e sello del dicho señor Rey e de los dichos perlados, e caualleros, e signadas de escriuano público, según dixo que se contenía en vna carta del dicho señor Rey, firmada de su nonbre e sellada e sobreescripta del doctor Fernando Días de Toledo, su oydor e rrefrendario; el tenor del qual capítulo e carta dixo que hera el seguiente (HALCO: 80-81).

(7) nos despedimos della habrá ocho días; y, habiendo seis que llegamos a la aldea de Grisaldo, jamás he podido hallar lugar de hablarle a solas, como yo deseaba, hasta esta mañana que supe que venía a caza, y le aguardé en el mesmo lugar adonde él se despidió. Y he pasado con él todo lo que vosotras, amigas, habéis visto, del cual venturoso suceso quedo tan contenta cuanto es razón lo quede la que tanto lo deseaba (GALA: 185v).

Cuantitativamente, se observa el alto predominio de la función Sujeto como papel cumplido por estas estructuras; le siguen los valores de Objeto Directo y Complemento Circunstancial; el resto de funciones tiene una incidencia en el conjunto de la base de análisis que puede calificarse de poco relevante, como se manifiesta en la tabla que sigue:

\begin{tabular}{|l|c|}
\hline \multicolumn{1}{|c|}{ FUNCIÓN } & NÚMERO DE OCURRENCIAS \\
\hline Sujeto & 445 \\
\hline Cto. Circunstancial & 199 \\
\hline O. Directo & 105 \\
\hline Cto. del Nombre & 19 \\
\hline Cto. Régimen & 7 \\
\hline O. Indirecto & 5 \\
\hline Cto. del Adjetivo & 5 \\
\hline
\end{tabular}

La inclinación de estas expresiones por ocupar funciones de sujeto puede explicarse por la posición preferentemente encabezada que ocupan en la frase, sólo quebrantada por los complementos nominales - y ni siquiera en todos los casos dentro de esta función-. Esa colocación influye en el papel de alta prominencia temática que suele desempeñar, manifiesto también en la 
posibilidad de que tal posición propicie la aparición de nuevos vínculos anafóricos dentro de la estructura introducida por cual y que remiten a ella de nuevo, por ejemplo en la siguiente cita, donde el sintagma que reduplica a la estructura con cual aporta, frente a la construcción relativa, un significado de interpretación distributiva manifiesto en cada:

(8) E la torre estava cercada de una cerca vien alta, con cuatro torres, e luego su barrera [...] En las quales torres estavan en cada una dellas una dama vien arreada (HALCO: 20-21).

Hay también en el corpus despojado algunas muestras en que una estructura con <cual + antecedente adjunto> con función de objeto directo concurre en la misma frase con un clítico acusativo. Los ejemplos son todos ellos medievales, aunque justamente la duplicación de pronombre para OD sea todavía un hecho minoritario durante la Edad Media; el hecho de que el OD esté a la izquierda del verbo y a principio de frase es un factor que, obviamente, está favoreciendo la duplicación (vid. para más ejemplos cuatrocentistas Eberenz 2000: 203).

(9) sean tenudos de dar por censo cada año en tal fiesta atal monesterio una libra de çera o una meaia de oro el qual censo prometio el sobredicho de pagarlo assi (7PAR: ley 69, partida 3).

(10) E quando estas dádybas dió, avn no se abía fecho las barbas con nabaja, las quales barbas él las fizo miércoles en la noche (HALCO 9).

(11) Pero si más tu esperança detienes, faltarán mis razones para que te diga, pero no mal para que me quexe, el cual quexar más en los lloros que en la lengua lo verás (ARNA: 114).

(12) La cual dicha escriptura de asiento, capitulación e concordia suso encorporada, vista y entendida por Nos y el dicho Príncipe D. Juan nuestro Hijo la aprobamos (DOC 39).

En otros casos, <cual + antecedente adjunto $>$ introduce un referente que está coindizado con un elemento de significación posesiva dentro de la oración que encabeza, sea un sintagma nominal con posesivo $(13,14)$ o un sintagma nominal modificado por un complemento introducido por de, sintagma que equivale a una relación de posesión similar a las de posesivo antepuesto (15):

(13) $\mathrm{Tu}$, rrey, veyas e ahe un ydolo grande, el qual ydolo tal su rresplandor era mucho leuantado en frente, e su vista era terrible (BIB cap. 2 Daniel).

(14) tres cavalleros que venían al paso, e el uno alemán, e los otros dos aragoneses de la ciudad de Valencia del Cid de los del reino de Aragón; al qual alemán llamavan por su nonbre miçer Arnaldo de la Floresta bermeja del marquesado de Brandambruco, que es en la alta Alemania, el qual cavallero era su edad, poco más o menos, ventiséis o veintisiete años (PASO: 108). 
(15) segunt se contiene en una carta escripta en papel e seellada con sus siellos de çera en las espaldas, de la qual carta el tenor della es este que se sigue (NOG14: $276,1352)$.

En estas tres frases se refleja la competencia que el cual supone para el pronombre relativo posesivo cuyo, en la última integrado como complemento con de y repetido por otro complemento preposicional paralelo; en las dos primeras, en cambio, en una configuración con el cual... su que recuerda a la fórmula que... su que hoy sirve también para reemplazar a cuyo pero que es insólita con el relativo el cual.

El examen del tipo de sustantivo que se selecciona como antecedente y se adjunta no revela aparentes condicionamientos ni restricciones. Como sustantivo adjuntado al relativo el cual hallaremos a nombres de referente abstracto o concreto, individual o colectivo, nombres propios y nombres comunes. Como único dato de interés se puede señalar la alta frecuencia que algunos sustantivos presentan en su uso como adjunto a lo largo de todo el corpus. La fórmula más repetida es la(s) cual(es) cosa(s) con cincuenta y dos ocurrencias, forma presente a lo largo de toda la diacronía estudiada. Propias de tradiciones discursivas jurídicas y notariales son las formas la(s) cual(es) carta(s) con treinta y una apariciones y la(s) cual(es) pena(s) con catorce muestras. La recurrencia de estas estructuras condice con el carácter altamente formulaico de tales tipos textuales; en el resto de textos estudiados no se percibe ese fenómeno de repetición propio de lo jurídico, notarial, administrativo, y, por ejemplo, un sustantivo como hombre sólo deja cuatro ejemplos en el corpus, lo que da idea de lo variado del catálogo de sustantivos que puede aparecer en uso de adjunto.

El tipo de sintagma que se introduce con el cual + sustantivo adjunto suele ser [artículo + relativo + antecedente adjunto], pero también puede hallarse otra variable, menor en cantidad, consistente en la interposición de adjetivo entre el relativo y el antecedente. Tal adjetivo es, muy comúnmente, dicho, refuerzo de la misión anafórica que tiene encomendada la estructura relativa. A dicho lo hallamos de forma preferente en tradiciones discursivas ligadas a la jurisdicción, el mundo administrativo y notarial. Veintinueve de los cuarenta ejemplos en que dicho aparece reforzando el reenvío a un antecedente previo figuran en textos de las tradiciones discursivas mencionadas, y ello ocurre desde el siglo XIV, y se prolonga más allá de la Edad Media:

(16) fago carta de donaçión, que por todos tienpos sea valedera, e do a la abbadesa e comento del monesterio de Santa María de Caruayal, que es çerca la dicha çibdat de León vnas casas con so sonbrado e corral, que yo he aquí, en la dicha çibdat de León, a la collaçión de Santo Pedro de Santo Ysidro; las quales dichas casas determinan: de la primera parte e de la segunda [...] (CARB14: 381, 1376). 
(17) E nos, las sobredichas abbadesa e comento, dámosvos en troque e concanbia por la dicha heredat la huerta que nos hemos e nos a nos pertenesçe e pertenesçer deue por parte del dicho nuestro monesterio, con todos sus iuros e derechos e pertenençias, e con entradas e con salidas quantas ha e auer deue; la qual dicha huerta es en el arraual desta dicha çibdat, çerca el monesterio de Sant Clodio de la dicha çibdat, la qual dicha huerta ha por linderos [...] (CARB14: 385, 1377).

(18) mandó publicar un edicto en nombre de su hija Doña Juana, llamándola Reina de Castilla, León y Granada y Princesa de Aragón y Castilla, llamándose a sí mismo gobernador y administrador de los dichos Reinos de Castilla, León y Granada por la dicha Reina su hija, el cual dicho edicto agraviaba mucho a la nobleza y vulgo de aquel reino (DOC: 213).

(19) Por manera que importan las alhajas y demas cosas de que se compone este último inventario, y segun las partidas que en él se refieren, ocho mil trescientos cincuenta y un reales de plata, y ochenta y seis mil doscientos sesenta y ocho reales de vellon como parece de esas sumas, en las que están escritas por menor en las siete hojas antes de esta, los cuales dichos bienes y alhajas se entregaron en virtud de órden de Su Majestad (VALE: 291-292).

Pero no sólo se trata de que haya un procedimiento - el empleo de cual con antecedente adjunto modificado por dicho- que resulte preferido por un tipo de tradición; la cuestión más interesante es que se observa que en otros muchos casos, la suma de dicho como refuerzo anafórico a la estructura con cual aparece en textos no jurídicos, no administrativos pero dentro de secuencias que sí invocan a ese mundo de la reglamentación legal. Por ejemplo, en un texto de naturaleza narrativo-historiográfica como la Crónica del Halconero dos de los cuatro casos de <el cual dicho + antecedente> se emplea en pasajes donde se presentan mandatos del monarca Juan II materializados en documentos legales formalizados $(20,21)$; igualmente, en la Visión delectable el único ejemplo que encontramos está en la explicación de los índices:

(20) veniese al dicho señor Rey, porque quería aver su consejo con él e con los otros de su rreyno que eran en su Consejo, sobre çiertas cosas justas, legítimas, rrazonables e onestas, según que en la dicha carta del dicho señor Rey de llamamiento se contenía, la qual dicha carta de llamamiento del dicho señor rey fué leyda en presençia del dicho conde de Castro (HALCO: 116).

(21) ORDENO e mando que los del mi Consejo de la justiçia guarden la ley e premática sención que yo fize e ordené para que todos los pleytos vayan a la mi Audiencia, e esto se entienda en los pleytos que de aqui adelante acaeçieren, $s u$ tenor de la qual dicha premática sención es este que se sigue (HALCO: 240).

(22) Tabla de los capitulos del libro llamado vision delectable, compuesto por alfonso dela torre bachiller a jnstançia del muy noble señor don johan de beamonte. El qual libro es diuidido en dos partes. Enla primera parte tracta dela artes liberales \& dela metaphisica \& dela natura. Enla segunda tracta dela philosophia moral. Los capitulos del qual dicho libro son diuididos enla siguiente forma (VISI). 
En La Pícara Justina sólo se da una vez y no propiamente en la obra, sino en las disposiciones legales de impresión que figuran en su encabezamiento; lo mismo ocurre en la Conquista de las islas Malucas de los Argensola, que repiten el texto de la misma licencia de impresión. Y la vez que se documenta en el Quijote pertenece al aparatoso discurso en primera persona de la dueña Trifaldi, en que ésta narra su cuita inventada de forma extremadamente ceremoniosa y con rasgos lingüísticamente muy cargados:

(23) $\mathrm{Y}$ mandamos que durante el dicho tiempo persona alguna sin vuestra licencia no le puedan imprimir ni vender, so pena que el que lo imprimiere o vendiere haya perdido y pierda cualesquier libros, moldes y aparejos que dél tuviere, y más incurra en pena de cincuenta mil maravedís por cada vez que lo contrario hiciere. De la cual dicha pena, sea la tercia parte para la nuestra Cámara, y la otra tercia parte [...] (PIC: 36, privilegio real).

(24) Y mandamos que durante el tiempo de los dichos diez años, persona alguna, sin la dicha vuestra licencia no pueda imprimir ni vender el dicho libro, so pena que el que lo imprimiere y vendiere haya perdido y pierda todos $\mathrm{y}$ cualesquier libros, moldes y aparejos que del dicho libro tuviere; y más, incurra en pena de cincuenta mil maravedís, la cual dicha pena sea la tercia parte para la nuestra Cámara, y la otra parte para el juez que [...] (MALU: 3).

(25) Del famoso reino de Candaya, que cae entre la gran Trapobana y el mar del Sur, dos leguas más allá del cabo Comorín, fue señora la reina doña Maguncia, viuda del rey Archipiela, su señor y marido, de cuyo matrimonio tuvieron y procrearon a la infanta Antonomasia, heredera del reino, la cual dicha infanta Antonomasia se crió y creció debajo de mi tutela y doctrina, por ser yo la más antigua y la más principal dueña de su madre (QUIJ: II, 38.942).

En resumen, la adjunción de dicho es indicio de pertenencia del texto o de la secuencia en que se inserta al ámbito de lo legal (de forma real o de forma paródica, como en el Quijote); fuera de ese ámbito, dicho aparece muy escasamente y no a partir del siglo XVI ${ }^{7}$. De menos interés para el análisis es la modificación a la derecha del adjunto, hay muestras de reforzadores de foricidad, como sobredicho; se da, de nuevo, el cuantificador todo $\mathrm{y}$, en escasísimo número, los adjetivos. Sí es relevante esta posibilidad en tanto que es consonante con lo que ya hemos dicho: la estructura prototípica es [artículo + cual + antecedente adjunto] y la modificación (anterior o posterior al adjunto, o anterior al relativo) es poco numerosa y se da, sobre todo, con elementos que fortalecen la foricidad o que sirven para encerrar y englobar a lo previo (todo). ¿Se ha limitado de alguna forma la capacidad de adquisición argumental de la estructura para limitar también su carga fonética, ya de por sí pesada?

4. En función de la relación entre el núcleo nominal que se incorpora a el cual y el antecedente del relativo, podemos separar dos usos según si el antecedente 
endofórico es reproducido fielmente, copiado, o si es casi copiado, alterado o reformulado. Para la explicación del mecanismo que crea un lazo cohesivo mediante el envío correferencial a algo previamente mencionado ha tenido mucha difusión la distinción que Fernández Ramírez (1951) empleó en su momento para aludir a los distintos tipos de deíxis que podía establecer un demostrativo: anáfora etimológica (remisión con mención literal a lo ya nombrado) o anáfora difusa (remisión con elaboración conceptual de lo ya nombrado; Fernández Ramírez se refería sobre todo a aquellos casos en que el antecedente es oracional). Esta misma distinción fue aplicada por Elvira (1985) y posteriormente por Iglesias Casal (1996: 62-163) para explicar estos dos usos. Que una terminología inicialmente pensada para los demostrativos se ajuste en la práctica a los usos de el cual con antecedente adjunto ya avisa de la semejanza en el funcionamiento fórico de ambas categorías.

Si separamos los casos de copiado literal del antecedente en el adjunto (copiado) de aquellos en que el antecedente es reelaborado, desarrollado o acortado cualitativamente (alterado), tenemos que domina el copiado literal del antecedente, con un $63,4 \%$, en tanto que el antecedente convertido en adjunto alterado aparece en un $36,6 \%$ de las ocasiones. Los siguientes datos numéricos sobre cifras de anáfora con copia o con alteración reparten tal estadística por siglos:

\begin{tabular}{|c|c|}
\hline Siglo & $\begin{array}{c}\text { Porcentaje de } \\
\text { antecedentes alterados }\end{array}$ \\
\hline XIII & $25,6 \%$ \\
\hline XIV & $15,4 \%$ \\
\hline XV & $33,3 \%$ \\
\hline XVI & $61,7 \%$ \\
\hline XVII & $35,7 \%$ \\
\hline XVIII & $0 \%$ \\
\hline XIX & $12,5 \%$ \\
\hline
\end{tabular}

No es posible señalar una línea de comportamiento cambiante con el avance del tiempo. En todo caso, la bajada en cantidad de casos de alteración desde el siglo XVII es solidaria con el propio descenso de documentación de la estructura. Y, por otro lado, desde los siglos XIII al XVI conviven alteración del antecedente y copiado literal con diferencias apreciables en función de la tradición discursiva que sometamos a nuestra consideración.

Conviene discernir entre clases de alteración en la conversión del antecedente en adjunto para poder desbrozar internamente esos datos. La primera frontera se ha establecido entre los adjuntos que copian literalmente, etimológicamente, a sus antecedentes o los que lo alteran, los cambian, los reelaboran; ahora bien, esa frontera establece divisiones radicales. Igualmente, tampoco parece posible constituir un eje polar entre antecedentes copiados, en 
un extremo, y antecedentes completamente cambiados, en otro ${ }^{8}$. A lo sumo, se pueden catalogar - en un conjunto de separaciones limitadas que los agrupen y alejen a la explicación del peligro de la casuística y la aclaración ad hocalgunos tipos de operaciones formales que en el proceso de toma del antecedente y conversión en adjunto implican algún cambio. Partiendo de la separación en anáfora etimológica y difusa que realizó Fernández Ramírez, la que presento aquí incide en la relación que contrae el adjunto con su antecedente semántico; más específicamente se separan dos grandes grupos:

(i) El adjunto repite un lexema mencionado en el enunciado anterior, literalmente o no (con nominalizaciones, derivaciones, cambios morfológicos, etc).

(ii) El adjunto reenvía al enunciado anterior sin repetir ninguno de los lexemas que este menciona, sino a través de un encapsulador, un sinónimo, un hiperónimo o un elemento que se infiere de lo precedente.

En los casos de (i) separaremos cuatro tipos de repetición lexemática del antecedente en el adjunto: repetición literal del antecedente (o copia), repetición con variación morfológica o derivativa y nominalización de una expresión verbal o una propiedad previas.

La repetición literal supone la copia exacta del antecedente, con su misma forma (sustantivo > sustantivo) y marca numérica. Este ha sido el tipo de remisión anafórica medida en el cuadro anterior bajo la etiqueta de "copia”. Las construcciones con repetición literal del antecedente adjunto son las que dominan en el corpus desde las primeras centurias hasta el final del arco temporal estudiado:

(26) E fue puesta Briseyda en el monesterio de Laçedemonia. E sabet que esta Egeal era fija de Polyniçes, fijo de Edipo e de Jocasta. El qual Edipo mato a su padre el rey Layo e caso con su madre Jocasta, madre deste Poliniçes (LEO: 279); En agosto de este mismo año supo que habían salido del Cuñal diez y ocho galeotas, y por capitán de ellas Cutumuza, ayudado del Rajú, con designio de cercar la fuerza de Zeilán; el cual Cutumuza en el año pasado había quemado una nave nuestra que pasaba a la China, y hecho lloroso estrago en la costa de Charamandel (MALU: 169); los dichos embaxadores ovieron de estar en esta ciudat de Pera todo el invierno, que no pudieron fallar nabío más presto que una galeota de diez e nueve barcos; e fiziéronla armar, que les costó asaz dinero. La cual galeota fue armada e presta para en el mes de março (TAMOR: 160).

Puede darse también una repetición del antecedente nominal con variación morfológica o derivativa, esto es, manteniendo invariable la raíz lexemática y dándose cambios morfológicos. El más común de tales cambios supone que el adjunto recoja en singular un antecedente originariamente plural, aunque es frecuente la modificación contraria: 
(27) et diome actoridat e poder conplido para que feziesse fed de las notas e escripturas que en ellos fallase que eran las cartas por fazer, por la qual nota pareçía quer era la carta por fazer, e el tenor della, según el curso de las boras, es éste que se sigue (CARB14: 1357, pág. 367); E mandó fazer sus pregones por Escama, su faraute e mariscal de armas, con su justiçia e tronpetas, el qual pregón era contra los que dentro en la mota estauan, e cada vno nonbrado por su nonbre (HALCO: 397).

(28) de la fuente de los peros boldrones dexieron que a vos Pero Rodrigues de cada quatro dias, tres dias agua e Pelay Qeyada el uno. E de la fuente del carril disen los que uendieron la heredat a Pero Rodrigues que a dos dias Pero Rodrigues de la parte de Alfonso Martines Quadrado e de la parte de Domingo de Veyga e de su hermandar otro dia, e Monio Suares otro dia por parte de Domingo Garcia. Las quales heredades e bienes sobredichos, cada unos por parte de los sobredichos [...] (NOG14: 324); volvieron e su camino fizieron, ellos e el rey de armas e faraute sin más tardar a las tiendas donde estava el generoso capitán Suero de Quiñones, que se començava de armar, a la qual tienda llegados, falláronlo armado (PASO: 146).

No hay cambio en el valor referencial al modificarse el valor genérico de la singularidad hacia la pluralidad, dado que en los ejemplos el antecedente suele recoger ya valores plurales que se plasman sintácticamente en el adjunto. Un caso claro es este paso del singular genérico al plural morfológico:

(29) y porque mi intención es mostraros cómo se pueda ordenar un ejército, en la tierra donde no se usa milicia: en las cuales tierras no se puede haber elección para usarlos luego (MILIT: 120-121).

Más raras son las ocurrencias en que el adjunto experimenta un proceso derivativo con respecto al lexema que funciona como antecedente; tal derivación puede ser apreciativa (30), pero, sobre todo, se encuentra derivación nominal de sustantivo a sustantivo (31):

(30) E otrosí sacaron de aquel talegón una arqueta de oro más pequeña que la primera, e dentro en ella estava una buxeta engastonada en ella que no se podía della quitar. La cual buxetilla era de cristal, e dentro en ella estava de la sangre de Iesu Christo (TAMOR: 139).

(31) Y tuvo tan buena mano este rey Nino en esto, que é sojuzgó muchas tierras y provincias y las dexó a sus sucessores, y duró el reyno y señorío en sus descendientes (según escrive el mismo Augustino, Eusebio y Diodoro Sículo) mil y trezientos años, la qual sucessión fue de padre a hijo, en todo este tiempo, sin faltar herederos (SILV: 230); Basta que sepas que todos sus enamoramientos denotan maneras de amores y de amistades, que dependen de la influencia de Iupiter en aquellos en cuya natiuidad el domina. El qual influxo vnas vezes lo da el solo (DIAL: 339). 
En total, una veintena de ejemplos en que el antecedente nominal es repetido casi literalmente en el adjunto con una mera variación morfológica o derivativa; cronológicamente, las muestras parten del siglo XIII y no superan el siglo XVII.

En los casos de nominalización, el adjunto no remite a una expresión nominal antecedente sino a toda una expresión predicativa. La naturaleza forzosamente nominal del adjunto que se asocia a el cual obliga a convertir en nominal una expresión predicativa previa que contiene un verbo. Es este elemento (el verbo) el que da nombre al conjunto de la predicación anterior en cuanto enunciado y que se incorpora como adjunto en forma de sustantivo. Esta copia de antecedente sin mantenimiento de su categoría formal es un procedimiento de mayor regularidad e insistencia en el corpus, desde el siglo XIII al XIX, con más de una treintena de evidencias. El verbo retomado puede figurar en forma no finita o finita $(32,33)$, y puede ser retomado por una forma nominal infinitiva, que puede suponer, incluso, una copia formalmente literal de un infinitivo verbal anterior (34):

(32) Otrosí para mientes al juyzio que dio Dios por la muger que le traxeron delante que fue tomada en adulterio e cómmo quisieron tenprar los judíos por razón desta muger, del qual tenpramiento se guardó Él muy bien (CAST); Que los granujas de la vecindad habían pegado fuego a un montón de paja que en mitad del patio había, y después robaron al maestro Curtis todas las eneas que pudieron, y encendiéndolas por un cabo empezaron a jugar al Viático, el cual juego consistía en formarse de dos en dos (FORT: 3.6.4).

(33) E cómo llegó a Roa, adolesció e murió; de la qual muerte el señor Rey e el condestable, e todos los otros cavalleros e gentiles omes que a la sazón estauan en la corte, fueron muy pesantes (HALCO: 252); Y quanto al accidente se puede ordenar, de manera que cada año los capitanes los muden de las provincias, porque la continua autoridad sobre unos mismos hombres, engendra entre ellos tanta unión que fácilmente puede causar perjuicio: las cuales mutaciones cuanto sean útiles a los que las han usado, y dañosas a quien no las observa, se conoce por el ejemplo del Reino de los Asirios (MILIT: 124); y la fama del truhán español por toda ella volaba, hasta tanto que ya en casa del padre de Nísida me deseaban ver, el cual deseo les cumpliera yo con mucha facilidad, si de industria no aguardara a ser rogado (GALA).

(34) E luego otro día fueron comer con él; en el cual comer ovo asaz viandas, adovadas segund su usança (TAMOR: 212); Pero si mas tu esperança detienes, faltarán mis razones para que te diga, pero no mal para que me quexe: el cual quexar más en los lloros que en la lengua lo verás (ARNA: 114).

Puede también nominalizarse una propiedad del antecedente: el adjunto se origina a partir de una propiedad o atributo del nombre; tal propiedad se convierte en expresión de una propiedad genérica de la que se predica a continuación algo. En última instancia y por una vinculación de orden metonímico, se efectúa una transición generalizadora. Con todo, este 
procedimiento de toma de antecedente es raro, sólo deja nueve ejemplos, que se concentran en cuatro de las obras analizadas:

(35) Los sus pannos deste rey eran orofresados en aljófar e con piedras preciosas, la qual orofresadura se demuestra los galardones de bien que deue dar el rey a los que lo meresçen seruiéndole bien e faziendo buenas obras (CAST: 11); E vino después armado otra vez, solo en su cavallo, e syn tronpeta nenguna, con vnos paramientos muy rricos, vordados de oro. La qual vordadura eran esperas (HALCO: 24); El Macrobio dize que las donzellas no se casavan en día de fiesta porque, como está dicho, se hazía cierta cerimonia de tomar las donzellas forçadas de las faldas de la madre; la qual fuerça, fingida nin verdadera, non se podía hazer en día de fiesta (SILV: 636); El alboroto que Demogorgon sintio en el vientre del Caos, es la potencia y apetito de la materia confusa a la germinacion de las cosas divisas; la qual diuision causaua o suele causar tumulto (DIAL: 330).

En los casos de (ii), cuando el adjunto no reproduce a ningún lexema previo, el sustantivo retoma semánticamente todo el enunciado anterior o una parte de él, pero sin captar ninguno de los significantes que se alinean en ese decurso previo. Éstos pueden verse reemplazados por sinónimos, hiperónimos, encapsuladores o reasuntivos con calificación discursiva.

El más simple de estos mecanismos de sustitución implica el uso de un adjunto a el cual que es sinónimo de la expresión nominal que funciona como antecedente. Este procedimiento, que implica la diferencia lexemática con identidad sémica de las dos entidades, antecedente y adjunto asociado a el cual, es raro antes de fines del XV, y más común - aun dejando pocos rastros: sólo nueve ejemplos, si bien repartidos en obras varias - a partir de esa fecha $y$ hasta el XIX.

(36) En la tal morada, segúnd diximos, mora la Discreçión. La qual casa está apartada çinco millas lexos de la más floresçida çibdad de Tiscana (PERF: 150); y principalmente han de entenderse los señores helvéticos, que mediante su consentimiento desde ahora están comprendidos e incluidos en esta alianza según la forma de los capítulos de la existente entre nuestro santísimo señor y los señores de Helvecia, a la cual liga hay que dar plena satisfacción (DOC: 268); Muchos de los antiguos escritores escrivieron, muy excelente señor, y en diversas formas, para por diversas maneras poder aprovechar a los letores. Entre los cuales autores, los cómicos y ordenadores de comedias fueron muy acetos comúnmente a todos (SEGD: 105); Después llamó la atención de D.Evaristo la facha de un hombre que iba por entre las mesas, el cual sujeto más bien parecía momia animada por arte de brujería (FORT: 3.4 .8 ).

En esa cadena de continuidad sémica, el sustantivo adjunto puede añadir en forma de sinónimo datos aclaratorios sobre el antecedente; así, este ejemplo del Arnalte en el que la remisión es más bien catafórica del antecedente al adjunto que aclara la identidad del viejo que asiste a la presentación de Jesús niño: 
(37) fue cuando el Niño ofreciste / al viejo honrado en el templo; / el cual viejo Simeón, / que en virtud de Diuos fablava, / te denunció la Pasión (ARNA: 151$152)$.

O bien, puede añadir notas valorativas bajo la apariencia neutra de un sinónimo:

(38) Yo conozco un capellán de monjas, ancianito, buen cristiano, y que convierte gente mala, porque tiene un pico de oro, un gancho del cielo que es un primor; el cual curita me está diciendo siempre que le busque un ama de fundamento (DESH: 2.18).

Mecanismo emparentado con el de la sinonimia es el de la sustitución mediante expresión hiperónima: en esta subclase la cohesión textual se sostiene sobre una relación semántica basada en la referencia al antecedente a través de un sustantivo de menor intensidad semántica pero mayor extensión referencial, esto es, una expresión hiperónima. Hay más de una veintena de ejemplos de este tipo en el corpus; abundan los que recogen nociones básicas de tiempo y espacio, por ejemplo, remiten mediante el sustantivo tiempo a una determinada unidad de medida cronológica enunciada anteriormente con una expresión nominal:

(39) estonçe Ezechiel en hedad de treynta años, en el quinto año de la captiuidad escomenço a prophetizar alos captyuos, en el qual tiempo prophetizando Ezechiel en Caldea, prophetizaua Geremias en Judea (BIBL: prólogo de S. Jerónimo al libro de Ezequiel); cuando dende partió por su alcalde mayor podía aver seis años e onze meses en el cual tiempo aquel su alcalde dizen que usó mal del oficio (TAMOR: 278); como quiera que la maior antiguedad de letras entre ellos es en la edad de moisen: enel cual tiempo ia las letras florecian en egito (GRAM: 48); por cuanto que cada dia viene acercando el casamiento que se ha de hacer por la gracia de Dios entre mi señor [...] y la señora Doña Catalina, hija del Rey vuestro ilustre señor, cerca la fiesta de San Juan Bautista que viene, del cual tiempo su Majestad del Rey nuestro señor confía que se recordará (DOC: 215); la Yglesia tomana estuvo sin pastor y nuevo pontífice, por discordia de los electores cardenales, un año y un mes. Todo el qual tiempo avían estado juntos todos los cardenales para hazer su eleción (SILV: 569); lo que yo pensaba pedirle, porque ya le juzgaba por vencido, era que volviese a su lugar y que no saliese dél en todo un año, en el cual tiempo podría ser curado (QUIJ: II.65).

o bien (menos frecuentemente) con el sustantivo lugar o espacio a una entidad de índole locativa ${ }^{10}$ : 
(40) se podrían reducir en un cuadro, y ponerlas al costado de los dos batallones que yo pongo en la postrimera orden del ejército, desde el cual lugar podrían todas favorecer la frente, y espaldas del ejército muy fácilmente (MILIT: 181-182); hacían entorno [sic] de sus ejércitos sus estacadas, y delante de ellas las cabas que por lo ordinario eran anchas de vi codos y hondas iiii o a lo menos tres; el cual espacio acrecentaba, o menguaba según querían detenerse poco (MILT: 232); Y luego las pastoras, siguiendo a los pastores que guiaban, al son de muchos pastoriles instrumentos, hacia el templo se encaminaron, en el cual espacio le tuvieron Elicio y Erastro de cebar los ojos en el hermoso rostro de Galatea $(\text { GALA })^{11}$.

Otros hiperónimos hacen referencia a otras realidades concretas:

(41) E este día, desque el Señor e sus mugeres ovieron bebido una grand pieça, truxieron de comer muchos cavallos e carneros asados, pelados, e muchos carneros desollados. La cual vianda traían en unos muy grandes cueros (TAMOR: 296); diziendo que la cabeça chica assí es mala como el pecho muy angosto: porque el pecho es aposento del coraçón y pulmones, los quales miembros no suffren, sin daño, angosta posada (SILV: 335); porque no habíamos comido sino solos palmitos, y no osábamos comer otras frutas por no comer la manzanilla, que es una fruta muy sabrosa, a modo de gordas guindas, la cual comida hincha las personas y algunas revientan (VIAJ: 76).

La aparición de los hiperónimos de tiempo y lugar se da desde el XIV y ya es forma rara a partir del siglo XVII, muy posiblemente sustituida por sintagmas con demostrativo como en ese tiempo, en ese lugar. Los hiperónimos secundarios son más tardíos y tienen un comportamiento cronológico y de documentación similar al de los adjuntos creados por sinonimia examinados en el apartado anterior. Estamos ante un procedimiento emparentado con el anterior: sinonimia e hiperonimia son, al cabo, relaciones de inclusión sémica; por ello, no es extraño que coincida el comportamiento cronológico de ambos mecanismos de cohesión.

El adjunto puede formular de nuevo todo el miembro enunciativo anterior, que es el que se tendrá en cuenta en la prosecución del discurso. Mediante una proforma léxica, esto es, una palabra imprecisa léxicamente, puede hacerse alusión a todo lo previo; si se recoge un predicado eventivo, se manifiesta la función encapsuladora del adjunto incorporado a qual ${ }^{12}$. El encapsulador más común es cosa:

(42) E en otro tienpo el fuego ardia enla agua sobre la virtud de cada parte, porque destruyese la nasçion de la tierra pecadora. Por las quales cosas con manjar de angeles mantuuiste el tu pueblo (BIBL: 16. Sabiduría); Porque los varones militares ya ferozes y crudos por el uso de las armas, y por la mayor parte empleados en llagas y ríos de sangre, por la mesma exerçitaçión alcança 
sus ánimos a soberviosos deseos de señorear. Por la qual cosa se faze contrario a sus costumbres el obedesçer (PERF: 182).

Pero también puede emplearse un encapsulador de naturaleza semántica más precisa en comparación con cosa pero más vaga referencialmente como causa, razón, empresa:

(43) Ni osaua el Rey yr por causa de las dichas diçensiones [sic] e discordias, rreçelando que el Prínçipe don Enrrique su fijo, con otroa algunos del rreyno, se levantaría e farían algunos voliçios, en mucho deseruicio suyo e daño de su rreyno. Por las quales causas los moros avrian logar de fazer tanto mal e daño (HALCO: 498).

(44) Ca vemos muy buenos árboles que en el estío lievan fruto, pero sobreviniendo el otoño, dexan la foia, y después, al tiempo del yelo, pareçen estar secas. Por la qual razón, es de creer que el tiempo no trae poco provecho (PERF: 186).

(45) Sosegado el motín del Albaizín, tomó el conde de Tendilla a Güéjar sin contradición, después de aver seido resistido en un combate, pasando a cuchillo los moradores y defensores en la guerra, y vuelto a aloxar en Quéntar. En la cual empresa dizen que [...] se halló a servir (GRA: 9-10).

La referencia a lo anterior puede ser más específica y servir para resumir y calificar el contenido, aportando una definición reasuntiva para el referente global del enunciado; no faltan casos de encapsulamiento con definición que incluyen manifiestas notas valorativas:

(46) Commo Saturno quando fue fuyendo de su fijo Jupyter aporto en Ytalia e ouo en el camino a su fija Venus e a su fijo Mares e a su fija Palas e de su nombre tomo nonbre la tierra Saturna. Del qual lynaje de vno en otro vyno el rey Latyno de Ytalia e su fija Latyna que conpuso la gramatica e emendo el latyn (LEO: 362).

(47) Jamás quería ni procurava castigar al que dezía mal dél, sino quitarle la ocasión que tenía de dezirlo. La qual regla, si todos los hombres guardássemos, dos grandes provechos se siguirían (SILV: 584 ).

(48) Sostenida en hombros de los más autorizados, y en grotesco ataúd, se elevaba una figura bamboche formada de paja, y con vestido completo, el cual pelele era una vera effigies por su traje y hasta sus facciones del señor Marco (CURIO: 2.26.3).

(49) traýa Alexandre en su compañía y exército a Calístenes, philósopho; al qual, por cierta reprehensión que le hizo como hombre libre y sabio, Alexandre lo tractava muy mal y lo traýa metido en una jaula con los perros. La qual innominia y affrenta el ánimo virtuoso y libre del philósopho no quiso suffrir (SILV: 550-551); Tales son los pies del mundo inferior y sus mouimientos y transformaciones de vna esencia en otra transuersalmente, sin orden cierta; de las quales grosserias y desordenes estan priuados los cuerpos celestiales (DIAL: 333). 
De notable interés son los casos de anáfora inferencial, en los que se formula de nuevo el antecedente previo pero no a través de un lexema que resuma o evoque el miembro anterior sino a través de un lexema que remite a una realidad implícita en el enunciado precedente, del que emana una inferencia con la que se hila el discurso subsiguiente, sostenido sobre la coherencia de las relaciones de implicación entre ambos lexemas. Los casos son poco comunes, y se dan sobre todo a partir del siglo XV:

(50) E envíavos rogar que tomedes plazer e non tomedes enojo; e con estas buenas nuebas que vos trayo, demándovos por merced que querades oy bever e comer comigo. El cual vino traía consigo luego, en el cual venia la poçonia para con que lo avía de matar (TAMOR: 339).

(51) escribió a este conde de Castro el Rey, con vn fijo suyo que llamaua don Diego, a Segobia, donde estaua con el Prínçipe don Enrrique. El qual conde tenía al Príncipe, por mandado del Rey su padre. La qual carta era de rrequerimiento, que mandase a don Fernando [...] (HALCO: 398).

Por último, el sustantivo adjunto a cual puede funcionar de calificación discursiva de lo previo, esto es, estamos ante adjuntos con los que se reasume lo precedente no en cuanto enunciado sino en cuanto enunciación. El adjunto, en efecto, puede calificar a lo antepuesto en cuanto acto de habla o en cuanto tipo de texto, considerándose no el aporte referencial del enunciado sino lo que implica globalmente en cuanto a elemento incluido en el discurso:

(52) E estandolas talando, saliera a ellos el ynfante don Enrrique con doçientos de a cavallo e cuatrocientos omes a pie, e trabó el escaramuça; por tal manera que el ynfante don Enrique e los suyos fueron puestos por las puertas de la villa de Alborquerque. E fueron presos, del ynfante, Garçía de Giar e Gomes Mexía, dos omes que él quería muy gran bien, e muertos pieça de peones suyos. De las quales nuebas el señor Rey ovo gran plazer (HALCO: 137); De Abraham, por sucession de Isaac y de Jacob y de Leui, vino la tradicion, segun dizen, a los sabios de los hebreos, llamados cabalistas. Las quales noticias dizen auer sido confirmadas por Moysen por rreuelacion diuina (DIAL: 31).

(53) la clara e deuina generaçion dardana que so el tu duro e espantable sennorio es te dizen que sueltes los graues decretos de la sugeçion tanto tiempo dellos sofrida e quieras darles tierras de lybertad en el tu reyno e averlos de aqui adelante por tus fyeles amigos. E do esto non te plaze dales la salyda que vayan a buscar tierra en que pueblen, e esto que sea con la tu liçençia. Del qual pedimento tu estas debdor (LEO: 323); Y, al fin, todas concluían que Artidoro, el pastor forastero, había llevado la ventaja a todos, loándole cada una en particular sus particulares gracias; las cuales alabanzas, como ya he dicho, todas en mi contento redudandaban (GALA: 46v-47r). 
Esta función se observaba también en enunciados recogidos por la proforma cosa o también en ejemplos de (i) en los que el proceso de nominalización partía de un verbo de comunicación:

(54) e por más firmeza e seguridad de lo suso dicho juraron a Dios e á Santa María e á la señal de la cruz +, en que pusieron sus manos derechas, e a las palabras de los Santos Evangelios, do quier que mas largamente son escritos en anima de los dichos sus constituyentes, quellos e cada uno dellos ternán e guardarán e cumplirán todo lo suso dicho, e cada una cosa e parte dello, realmente e con efeto segun dicho es, e non lo contradirán: so el cual dicho juramento juraron de no pedir absolucion (DOC: 37); fue tratado y capitulado por Nos y en nuestro nombre, por virtud de nuestro poder con los dichos Reyes y Reina de Castilla, nuestros Hermanos, y con Don Henrique Henriquez, su Mayordomo Mayor y [...] todos del su Consejo, y en su nombre por virtud de su poder: en la cual dicha capitulacion los dichos nuestros Embajadores y Procuradores, entre las otras cosas, prometieron que dentro de cierto término [...] (DOC: 41-42).

5. De los aspectos estudiados hasta el momento, podemos sacar la conclusión de que no existen constricciones formales en el empleo de esta estructura; en cuanto al tipo de relación semántica que contraen el cual y el segmento al que señala, se observa una amplia virtualidad de relaciones sémicas posibles, aunque son las más simples las que perduran constantes en todo el decurso estudiado. El rasgo de mayor interés contrastivo entre su uso actual y su situación diacrónica está en su distinta frecuencia de uso, lo que nos lleva a plantearnos el origen de esta estructura y su cadena de difusión en español. Ofrezco una breve aproximación a cómo se distribuyen los ejemplos, en cifras que pueden ponderarse de acuerdo con la cantidad de textos despojados en cada centuria:

\begin{tabular}{|c|c|c|c|c|c|c|c|}
\hline SIGLO & XIII & XIV & XV & XVI & XVII & XVIII & XIX \\
\hline $\mathrm{n}^{\text {o }}$ ejemplos & 86 & 117 & 306 & 209 & 42 & 16 & 24 \\
\hline $\mathrm{n}^{\mathbf{o}}$ obras despojadas & 5 & 5 & 10 & 8 & 6 & 11 & 14 \\
\hline $\mathrm{n}^{\mathrm{o}}$ obras con ejemplos & 5 & 4 & 9 & 7 & 6 & 7 & 8 \\
\hline media por obra & 17,2 & 29,25 & 34 & 29,8 & 7 & 2,2 & 3 \\
\hline
\end{tabular}

Se observa cómo la estructura con antecedente está en ascenso desde el siglo XIII y en descenso desde el XVII. Una vez documentada en romance (más adelante veremos a partir de qué vía dentro de una misma textualidad de la distancia comunicativa) se halla ininterrumpidamente desde el siglo XIII hasta hoy: la encontramos profusamente en las Siete Partidas y en colecciones castellanas y leonesas de documentos notariales, también en el ámbito doctrinal, por ejemplo en los Castigos de Sancho IV: 
(55) E por este yerro non se guarda del lazo que el diablo le tiene armado fasta que cae en él de cabeça, del qual lazo nunca puede salir (CAST: 80).

(56) E este dicho suelo con su huerto, vos damos por otro suelo, que nos dades por el, que uos hauedes enno corral que va derecho de Aluar Diablo, con su palacio, del qual corral e del qual palacio vos cabe en partija el quarto [...] (NOG13: $162,1294)$.

Una búsqueda en CORDE - con el año 1300 como fecha ad quem - del sintagma la qual cosa, donde se integra el sustantivo más frecuente en esta estructura en el siglo XIII, es suficientemente reveladora. El sondeo ofrece cincuenta y cuatro resultados ${ }^{13}$, de los que veintiuno pertenecen a fueros y más de una decena a documentación, cartas pueblas, etc.:

(57) otrosi, si vno tan solamente fuere el omneçida, aquel solo sea desafiado \& non otro; por la qual cosa mando que por que [...] (Fuero de Cuenca).

(58) En sobreleuadura ninguno non sea reçebido si no aquel que touiere casa enla uilla con pendra; por la qual cosa non puede ninguna muger casamentada sobreleuar (Fuero de Zorita de los Canes).

(59) peche quanto danno por end uiniere de los robadores o de montadgo d'este conceio o del otro conceio o de otro castiello por yura de su sennor. Por la qual cosa mandamos que los pastores [...] (Fuero de Alcaraz).

En esta primera época, la estructura aparece muy raramente en otras fuentes de tipo narrativo; estas tendencias se perpetúan en el XIV: ningún caso en la Historia del rey don Guillermo de Inglaterra, pero ya sí algunos en las Sumas de la historia troyana, y en uno de los manuscritos de la Biblia romanceada, que incorpora ocho testimonios. Siguen dándose ejemplos en la escritura legal, pero vemos gradualmente cómo la materia narrativa ha adoptado esta configuración como un procedimiento de cohesión más, en paralelo a otros que iban, por ejemplo, alimentando gramaticalizaciones de conectores.

(60) E estauan ally todas las altas duennas de la tierra e avn otras de muy lexos tierra, entre las quales duennas estaua la muy fermosa Elena (LEO: 166).

En el siglo $\mathrm{XV}$, formas como la cual ciudad tienen un uso más frecuente, consonante con la moda que experimenta, en general, el empleo del relativo el cual frente a que (Lapesa 1966 [2000]); con todo, la historiografía o la escritura doctrinaria lo adoptan con mucha mayor frecuencia que la prosa literaria: 131 casos en la Crónica del halconero de Juan II, 29 muestras en el despojo parcial de El paso honrosso de Suero de Quiñones, 93 ocurrencias en Tamorlán pero sólo un par de ejemplos en el Tractado de amores de Arnalte y Lucenda y ninguno en La Celestina, al tiempo que sigue documentándose en ese siglo la estructura en documentación legal: 
(61) Aqui acabaron de romper sus lanças e cumplir las primeras armas en el paso, començadas por el generoso cavallero capitán mayor Suero de Quiñones, con el honrrado alemán; de las quales tres lanças, Suero rompió las dos (PASO: 153); E antes que los feziesen, mandólos prender; sobre la qual presión le scribió el Rey vna carta que adelante oyredes (HALCO: 362 ).

(62) Vuestra Majestad entenderá que a nuestra venida a la Corte del Rey estaba allí un embajador del Rey de los Romanos, el cual embajador había sido en algún tiempo secretario del duque de Milán (DOC: 225).

Tampoco la Segunda Celestina, en el siglo XVI, acoge ejemplo alguno de esta estructura, exceptuando uno en sus preliminares legales, fuera de la pluma de Feliciano de Silva. Continúa y va en alza la ejemplificación en tratadística: si en el siglo XV se encuentran diez casos en el tratado de la Perfección del Triunfo militar de Alfonso de Palencia, en el XVI se multiplica en el Tratado de re militari de Diego de Salazar (cincuenta y tres ocurrencias):

(63) Pero en aquella fiesta que se devía otorgar a los mereçimientos de Gloridoneo, - a la qual fiesta sola que después de muchos tiempos meresçía pompa él avía venido de grado a reçebir los solenes dones [...] (PERF: 183).

(64) mas temen mucho la inutilidad que no esto, de la cual inutilidad alegan dos razones principales (MILIT: 117).

Es muy común (casi 100 ejemplos) en los Diálogos de amor de León Hebreo traducidos por el Inca Garcilaso, pero ya empieza a haber huecos en tipos textuales que usaban la cual ciudad sin reservas en el siglo XV: hay sólo tres muestras en la crónica De la guerra de Granada de Diego Hurtado de Mendoza. Y, si una miscelánea como la Silva de varia lección recibe a esta estructura profusamente, otra obra del mismo tenor, en cambio, ya a final del siglo, el Jardín de flores curiosas de Torquemada, apenas deja ejemplos. Es el inicio de una tendencia que se acusa aún más en el XVII, centuria que, sin duda, constituye el punto de inflexión en la historia de esta configuración. Sólo un ejemplo en la Retórica de Céspedes, si bien es obra corta; pocos ejemplos en la Conquista de la islas Malucas de los Argensola y en el Viaje del mundo de Ordóñez de Ceballos, en cambio, sigue habiendo muestras en documentación legal, frecuentes en proporción con la extensión de los textos:

(65) [Tras una relación-inventario] Todas las cuales dichas partidas son sus justas tasaciones (VALE: 169).

Esa curva descendente se acentúa en el siglo XVIII: falta en la Historia de la conquista y población de Venezuela de Oviedo y Baños y no está en muchos de los ensayos ilustrados, salvo en Luzán, que la aprovecha ocasionalmente: 
(66) Aquí el poeta, al parecer, no se finge loco; solamente puede ser que hablase de burlas, en el cual caso se podría dar pasaporte a este concepto (POET).

Con todo, no es repudiada la configuración en el siglo XIX, antes bien parece experimentar cierta recuperación y se da, aunque exiguamente, en el género novelístico decimonónico (diez ejemplos en Mesonero Romanos, cuatro en Fortunata y Jacinta, tres en Peñas arriba, uno en Larra), muy posiblemente por el tipo de construcción de la lengua de la distancia comunicativa que se practica en este siglo (cfr. Octavio de Toledo / Pons en prensa), donde, por influencia de la novelística histórica se resucitan arcaísmos áureos y se hace crecer en frecuencia rasgos de escritura de la distancia bastante lejanos de los patrones de lo hablado:

(67) Estando otro día en el mercado con su saco de garbanzos por delante, llegó a él un caballero bien portado seguido de un mozo; el cual caballero, mirado que hubo en la mano la calidad de los garbanzos [...] (CURIO: 2.23.3).

(68) Se devanaba los sesos en el torniquete de su desvelo para averiguar el sentido de tal fenómeno, y llegó a figurarse que de los restos fríos de Mauricia salía volando una mariposita, la cual mariposita se metía dentro (FORT 3.6.11).

(69) salió Hernando inmediatamente a buscar un maestro en el arte de curar, como se llamaba entonces generalmente a esos seres de suyo carniceros que llamamos en el día cirujanos, el cual maestro declaró que ninguna de sus heridas era moral (ENR: cap.23).

Los trabajos de Barra Jover $(2007,2008)$ se han ocupado específicamente de la evolución de el cual y otros elementos de cohesión nominal como procedimientos al servicio de la solidez del conjunto textual. Como subclase de el cual cohesivo, nuestras estructuras de cual + adjunto apoyan la interpretación del fenómeno que ha desarrollado Mario Barra. Según este autor, a partir del siglo XII se observa un paulatino proceso de sustitución de los usos deícticosanafóricos del demostrativo de primer campo este por elementos como el qual, el presente, el siguiente, el dicho, etc. aumentando el uso de redes correferenciales basadas en argumentos nominales, según él, a partir del contacto con recursos cohesivos similares de los textos latinos medievales y con un cierto reparto según tradiciones discursivas. Dado que en la tradición notarial prima el deseo de desambiguar por encima del desarrollo cualitativo de la referencia, se construirán anáforas reiterativas con el dicho, en tanto que la literatura preferirá el uso de anáforas denominativas con el cual; aun así:

cuando las dos tradiciones intercambian, por así decirlo, sus marcas, éstas se adaptan a sus características. Razón por la cual, la tradición notarial muestra una tendencia particular a utilizar el qual como determinante, uso en el que acaba siendo estrictamente reiterativo, mientras que la tradición literaria tiende 
a utilizar dicho sin artículo, uso en el que suele desencadenar procesos configuracionalmente marcados de topicalización (Barra 2008: § 4).

Efectivamente, los datos recogidos confirman que en el ascenso de la estructura interviene su paso desde textos ligados a la esfera jurídica, administrativa o legal al ámbito de lo doctrinario, lo histórico y tratadístico. Tradiciones discursivas más inclinadas a lo literario - esto es, aquellas donde el uso lingüístico parece orientarse más hacia un cultivo estético - rechazan históricamente esta configuración, y curiosamente, sólo la novelística decimonónica parece alejarse de esta tendencia. Por esa relación con una tradición discursiva como la jurídica, muy escorada hacia el ámbito de la distancia comunicativa, de lo concepcionalmente escrito, no es descabellada la idea de Barra cuando sugiere que el uso de el cual surge „por influencia del latín adstrático" (Barra Jover 2007), aunque pueda ser más discutible la vinculación que realiza (sólo apuntada en Barra Jover 2008) entre la incorporación románica de el cual en redes cohesivas de referencia nominal y tipo topicalizador (frente a un tipo relativo con uso explicativo donde el cual forma parte del tópico) con la difusión del latín medieval y las litterae según la conocida teoría de Roger Wright. Las evoluciones que Barra documenta desde los primeros textos castellanos con profusión de cohesión de argumentos nominales mediante demostrativos hasta los textos que ya insertan siguiente, tal, dicho, etc. suponen un ejemplo de progreso en la elaboración lingüística intensiva del idioma (Ausbau en el aparato teórico de Kloss 1952 [1978]; 1967) ${ }^{14}$ a la búsqueda de una mayor distancia comunicativa: más anáfora es también más continuidad referencial, más explicitud en la linealización del texto y menor entrega a la elipsis. Y esa distancia comunicativa se construye mediante el préstamo de una estructura de los textos a los textos, un cambio desde arriba (no reproduzco aquí el conocido esquema de Jacob / Kabatek 2001 sobre esta cuestión ${ }^{15}$ ) cuyo factor agente estuvo en el intento de elaboración en romance de una nueva lengua del derecho (fueros, Partidas) y que traspasó la tradición discursiva que lo adoptó desde la esfera jurídica latina.

Efectivamente, tras la etapa del latín clásico, esta estructura estaba sometida fuertemente a un condicionante de tradición discursiva: aparecía sobre todo en tipos textuales jurídicos, donde respondía a un deseo de claridad y desambiguación (Bassols 1956: §233). Su continuidad en romance la constatamos por su presencia en documentación latina peninsular de los siglos XII y XIII:

(70) damus Deo et monasterio Sancte Marie de Trianis atque domno Lupo instanti abbati, tuoque conuentui, pro animabus parentumque nostrorum, illam partem quam habemus in ecclesia Sancti Saluatoris de Gordaliza, cum omnibus suis pertinenciis, preter divisam, et omnem ecclesiam Sancti Christofori eiusdem uillule, cum suis quoque omnibus pertinenciis, eo modo, ut in ecclesia 
iam dicti martiris Christofori conuentus Trianensis unum sacerdotem contineat qui perpetuo diebus singulis in eadem ecclesiam Deo ostiam offerat salutarem, exceptis diebus trium minucionum atque diebus proprie carnis recreacionis ter quindenis in anno costitutis, in quibus diebus in monasterio eandem missam permittimus celebrare. (Documento de 1223; Colección documental del Monasterio de Trianos; Josefa de la Fuente Crespo. León: Centro de Estudios e Investigaciones San Isidoro, 2000, pág. 153).

(71) Sicut ista affrontaciones ostendunt vel assignant predictum agrum, sic dono vobis eum salvum et securum, franchum, liberum et quietum et sine omni mala voce de celo usque in abbissum, cum ingresibus et egressibus suis, omnibusque suis pertinenciis et pertinere debentibus, cunctisque suis melioramentis ibidem factis ac faciendis, ad omnem vestram voluntatem. Ita tamen ipsum habeatis, teneatis, possideatis, expletetis diebus omnibus vite mee, tamen non vendendo nec alienando nec impignando; quibus diebus finitis redatis predictum agrumcui ego voluero, mandavero sive ordinavero ingenuum, salvum et securum, et absque omni impedimento (Documentos de Casbas, por Agustín Ubieto Arteta. Valencia: Textos Medievales 21, 1966, pág. 87).

Con estos usos en latín, en el mismo latín que convivía con las lenguas romances de forma constante en la época medieval, hay que prescindir - pese a la conversión del correlativo latino en un relativo acompañado del novedoso elemento del artículo-, de la hipótesis de un origen autóctono, propio, particular, para la cual ciudad. Teniendo en cuenta que se da en castellano, al menos, desde el siglo XIII y que encuentra en un primer momento mayor eco y difusión en la documentación legal y notarial, se puede defender la influencia de los usos latinos en documentos legales hispanomedievales en la génesis de la forma castellana la cual ciudad. Y ello también explicaría el hecho de que se dé en otras lenguas romances, por ejemplo en francés (, princes doît estre large en dons et graces donner, Lesquelles choses auons assez prouué de notre Roy", ap. Blatt 1957: 163), muy acusadamente en italiano o en lenguas en contacto con el latín como el alemán.

La estructura es idónea para las tradiciones discursivas jurídicas: el relativo indica género y número del antecedente, que, por si hubiera posibilidad de anfibología, se asocia al propio relativo convertido en adjetivo relativo; frente a un uso equivalente en función discursiva como podría ser el del demostrativo (esta ciudad, esa ciudad), la cual ciudad ofrece una relación cohesiva de mayor elaboración: remite a un elemento que ha sido, históricamente, el relativo culto y lo hace con una técnica de junción que permite incluso redefinir al antecedente o nominalizar toda la predicación previa: el cual hecho, etc. Habida cuenta de la imposibilidad de calcar esta estructura y sus ventajas con el subordinante universal que en su uso relativo, se copia con la forma cual, acompañada de artículo, de manera que reproduce por completo las „ventajas” que tenía la propia forma latina. Otros cambios lingüísticos, también sorprendentemente rápidos, como el paso de esto es de construcción libre a 
reformulativa (Pons Bordería 2008) han sido explicados acudiendo al factor del contacto latinorromance. $\mathrm{Y}$ no se debe obviar un par de rasgos en común en los recorridos evolutivos de todos estos elementos: su surgimiento en el XIII y su relación con la lengua jurídica que busca sus medios lingüísticos al pasar del latín al castellano.

Respecto a la pérdida de la estructura, puede responder a un proceso global de menoscabo de la yuxtaposición paratáctica con el cual, puesto de manifiesto por investigaciones de Girón Alconchel (2003), que defiende que tal proceso estaba ya iniciado en la segunda mitad del XVII. Este proceso favorecería la sustitución de estas formas de cohesión mediante subordinación floja por formas cohesivas hechas explícitas en la sintaxis y no sostenidas tanto sobre relaciones pragmáticas. La caída de el cual paratáctico arrastraría también a una de sus configuraciones más específicas, la que llevaba antecedente asociado. De cualquier forma, no se puede juzgar aisladamente la historia de este procedimiento cohesivo, y es necesario ponerlo en relación con el desarrollo de otros mecanismos cuya historia aún no conocemos bien: por ejemplo, de qué forma y a costa de qué elementos experimentó privilegios de figuración la elipsis como procedimiento cohesivo en aumento desde fines del $\mathrm{XV}$ en adelante, cómo han evolucionado - si es que lo han hecho- los usos deícticos textuales de los demostrativos desde fines de la Edad Media al español moderno, qué papel han tenido en relación con ejemplos como la cual ciudad y ciudad que estructuras como ciudad la que que se documentan de manera latente en etapas diversas de la historia de nuestro idioma.

Sí es claro que el español moderno ha preferido organizaciones sintácticas como ciudad que a la cual ciudad, y, por los datos cronológicos de nuestro corpus y los aportados por Barra (2008), parece que una estructura y otra se sucedieron en el tiempo, esto es, que (1a) cayó en desuso al tiempo que crecía $(1 b)$ :

(1a) E oyó misa el Rey, e ellos aparte, la qual misa dio el obispo de León (Pero Carrillo de Huete, Crónica del halconero, pág. 66).

(1b) Oyó el Rey misa, misa que dio el obispo de León.

Si a partir del XVII formas como (1a) comienzan a escasear, y en el XVIII ni las Cartas marruecas ni Los eruditos a la violeta deparan ejemplos, en la primera de estas obras se encuentra (apud. Barra 2007: 8) este enunciado:

(72) De esta relación inferirás como yo: primero, que esta península no ha gozado una paz que pueda llamarse tal en cerca de dos mil años, y que por consiguiente es maravilla que aún tengan hierba los campos y aguas sus fuentes, ponderación que suele hacer Nuño cuando se habla de su actual estado. 
y los ejemplos crecen en la obra de Larra en el siglo XIX. En ese siglo también, por cierto, perduran estructuras que fueron muy frecuentes en el XVIII como $<\mathrm{el}+$ que relativo $>$ en relativas explicativas no oblicuas, una configuración de la que no puedo ocupar aquí pero que sin duda tiene relación con la que aquí describimos en cuanto a mecanismo de elaboración idiomática ${ }^{16}$ :

(73) Fue interrumpido aquí el ilustre Gerif por el alcalde del Ayuntamiento viejo por mil excusas y cortesías, las que subieron de punto así vio a María (Joaquín Estébanez Calderón, 1838, Cristianos y moriscos.).

Aunque no es la descripción de formas como (1b) el objetivo de este artículo, sí se puede apuntar una reflexión más: si (1b) es herencia de (1a), se han modificado en algo las propiedades discursivas del esquema original. En (1a) tenemos un mecanismo que dota de continuidad al discurso pero que lo hace mediante una estructura pesada, de carga fonética larga. La pesantez que se observa en ejemplos como los de (1a), que llegan a la actualidad, contrasta con la adscripción mucho más coloquial de $(1 b)$. Si este proceso de sustitución se dio supondría el reemplazo de el cual por que, el relativo más común y menos marcado, en una de las pocas estructuras que le eran vedadas. Ahora bien, no quiero decir con esto que estemos ante un cambio en cadena donde es sólo el declive de una posibilidad el que impulsa la frecuencia de la otra. Creo que estamos ante una manifestación de un cambio de más amplio alcance: la modificación de los mecanismos de construcción cohesiva del español clásico al moderno, uno de los rasgos que más radicalmente transforman la armazón discursiva de nuestro idioma, un elemento que contribuye a crear la impresión de modernidad que tienen ya para nosotros buena parte de los textos del XVIII sin que a veces sepamos localizar qué elementos están cifrando esa idea de actualidad.

6. Las estructuras con qual y antecedente adjunto (la qual çibdad) presentan un doble encadenamiento al discurso precedente: superficialmente, por el relativo y la yuxtaposición, profundamente, por el antecedente. La reproducción sin alteración del antecedente supone simplemente retomar su referencia para iniciar una nueva oración; su alteración da lugar a efectos discursivos de más alcance: se avanza mucho más en la progresión temática, puesto que se introduce un término nuevo que reelabora lo dicho. Estamos, pues, ante una posibilidad constructiva que sustancia la textualización del discurso a partir del incremento de la relación entre sus partes, a través del establecimiento de lazos nominales entre un enunciado y el que le sigue, con función de introducción de tema.

Para la historia sintáctica de nuestro idioma es una estructura muy representativa de un tipo de cambio lingüístico que está en la base de no pocos procedimientos cohesivos: su nacimiento no surge, como ocurre con otros 
cambios lingüísticos, de la convencionalización de una inferencia nacida en el intercambio comunicativo, sino del préstamo sintáctico desde una lengua a otra, con la particularidad de que, en este caso, las lenguas son distintas sólo en un plano sincrónico y coinciden las tradiciones discursivas de partida y de llegada de la estructura: del texto jurídico en latín al texto jurídico (o administrativo) que se intenta construir en romance. Desde su inserción, la qual cibdad transita por los textos sin que sea fácil imaginar que saliera alguna vez de ellos, todo lo más desborda sus primeros límites textuales para expandirse en otras direcciones discursivas. Cuando la estructura comienza a desaparecer, es posible pensar que es reemplazada por otros mecanismos textuales de cohesión, tal vez basados en formas de recurrencia con menor carga fónica. El cual es, en suma, uno de esos elementos más orientados a la distancia que a la inmediatez comunicativa. En la actualidad no es raro oír frases donde la forma lo cual sin preposición ni antecedente oracional se emplea como elemento tematizador como "Me llegaron cartas de embargo, lo cual yo le dije al del banco que no debía nada", habitualmente de boca de hablantes que desean hipercaracterizarse lingüísticamente acudiendo a un elemento cuya historia parcial hemos querido presentar aquí.

Sevilla, octubre de 2007

\section{Corpus}

7PAR.- Las Siete Partidas de Alfonso X, en ADMYTE II, Archivo Digital de manuscritos y textos españoles, 1999.

BOC.- Bocados de oro, Bonium o Mukhtar al-hikam (traducción anónima), en: ADMYTE II, Archivo Digital de manuscritos y textos españoles, 1999.

CAST.- Castigos del rey don Sancho IV. Edición, introducción y notas de Hugo Óscar Bizarri. Frankfurt am Main: Vervuert; Madrid: Iberoamericana, 2001. Medievalia Hispanica 6, pp. 71-330.

CARB13.-Colección documental del Monasterio de Santa María de Carbajal (1093-1461) por Santiago Domínguez Sánchez. León: Centro de Estudios e Investigación „San Isidoro", 2000, pp. 200-450 [documentos del siglo XIII].

NOG13.- Colección documental del Monasterio de San Esteban de Nogales (1149-1498). Gregoria Cavero Domínguez. León: Centro de Estudios e Investigación „San Isidoro", 2001, pp. 31-591 [documentos del siglo XIII].

BIB.- $\quad$ Biblia Romanceada. Biblioteca Nacional de Madrid. Ms.10.288. Estudio, anotación y notas de Francisco Javier Pueyo Mena. Madison: The Hispanic Seminary of Medieval Studies, 1996, pp. 3-355.

CARB14.- Colección documental del Monasterio de Santa María de Carbajal (1093-1461) por Santiago Domínguez Sánchez. León: Centro de Estudios e Investigación „San Isidoro", 2000, pp. 200-450 [documentos del siglo XIV]. 
LEO.- Leomarte: Sumas de la historia troyana. Edición, prólogo, notas y vocabulario de Agapito Rey. Madrid: Junta para la Ampliación de Estudios, Centro de Estudios Históricos, 1932 (Revista de Filología Española, anejo 15), pp. 61-365.

GUIL.- Historia del rey don Guillermo de Inglaterra. En: Dos Obras didácticas y dos Leyendas sacadas de manuscritos de la Biblioteca de El Escorial. Sociedad de Bibliófilos Españoles, XVII. Madrid (1878), pp. 159-249.

NOG14.- Colección documental del Monasterio de San Esteban de Nogales (1149-1498). Gregoria Cavero Domínguez. León: Centro de Estudios e Investigación „San Isidoro", 2001, pp. 31-591 [documentos del siglo XIV].

TAMOR.- Ruy González de Clavijo: Embajada a Tamorlán. Estudio, introducción y notas de Francisco López Estrada. Madrid: Castalia, 1999. Clásicos Castalia 242, pp. 77-357.

CISO.- Enrique de Villena: Arte cisoria. En: Obras completas I. Madrid: Biblioteca Castro, Turner, 1994, pp. 133-218.

PASO.- Pero Rodríguez de Lena: El Passo Honroso de Suero de Quiñones. Edición de Amancio Labandeira Fernández. Fundación Universitaria Española. Madrid, 1977. Despojo parcial: pp. 69-200.

VISI.- Alfonso de la Torre: Visión delectable, en: ADMYTE II, Archivo Digital de manuscritos y textos españoles, 1999.

HALCO.- Pedro Carrillo de Huete: Crónica del halconero de Juan II (a.1454). Edición y estudio por Juan de Mata Carriazo. Madrid: Espasa-Calpe: Colección de Crónicas Españolas, VIII, 1946.

ARNA.- Diego de San Pedro: Tractado de amores de Arnalte y Lucenda (1491). Sermón. Edición de Keith Whinnom. Madrid: Clásicos Castalia, 1973. Arnalte, pp. 87170. Sermón: pp.173-183.

PERF.- Alfonso de Palencia: De perfectione militaris triumphi. Ediciones críticas y estudio de Javier Durán Barceló. Salamanca: Ediciones Universidad, 1996, pp. 129-186.

GRAM.- Nebrija, Antonio de (1492): Gramática de la lengua castellana (1492).

CELE.- La Celestina, edición de Julio Cejador y Frauca. Madrid: Espasa-Calpe, 1913; $1984^{11 .}$

DOC.- Documentos inéditos para la Historia de España, tomo VIII. Madrid, 1952. (pp. 9-379) [,Tratados internacionales de los RRCC”].

SEGD.- Feliciano de Silva: Segunda Celestina. Edición de Consolación Baranda (1988). Madrid: Cátedra, Letras Hispánicas 284.

MILIT.- Diego de Salazar: Tratado de re militari (1536). Edición crítica e introducción: Eva Botella Ordinas. Ministerio de Defensa, 2000, pp.105-266.

TURQ.- Viaje de Turquía. Diálogo de Hurdimalas y Juan de Voto a Dios callando que trata de las miserias de los cautivos de turcos y de las costumbres y secta de los mismos haciendo la descripción de Turquía. Edición, introducción y notas de M. S. Ortola. Madrid: Castalia - Nueva Biblioteca de Erudición y Crítica.

GRA.- Diego Hurtado de Mendoza (1503-1575): De la Guerra de Granada (1569-1573). Edición de M. Gómez Moreno. MHE, XLIX. Madrid: 1948.

JARD.- Antonio de Torquemada, Jardín de flores curiosas. Edición de Giovanni Allegra, 1982. Madrid: Castalia, Colección Clásicos Castalia.

DIAL.- Diálogos de amor de León Hebreo (1590). Edición de M. Menéndez y Pelayo. En: Orígenes de la novela IV. Madrid: Bailly/Baillière e hijos, 1905-1915, pp. 278-459. 
SILV.- Pero Mexía: Silva de varia lección (1aa a 2ª parte, 1540). Madrid 1662. Edición de Justo García Soriano, Madrid: Espasa, 1933-1934, pp.169-837.

GALA.- Miguel de Cervantes y Saavedra: La Galatea. En: www.cervantesvirtual.com

JUST.- Francisco López de Úbeda: La pícara Justina. Edición de Bruno Damiani. Madrid: Porrúa Turanzas, 1983, pp. 53-425.

RET.- Baltasar de Céspedes: Del uso y exercicio de la rhetórica (1607). Edición de José Rico Verdú en: La retórica española de los siglos XVI y XVII. Madrid, 1973, pp. 356364 .

QUIJ.- Miguel de Cervantes y Saavedra: El Quijote. Edición dirigida por Francisco Rico. Barcelona: Crítica, 1999.

VIAJ.- Pedro Ordóñez de Ceballos: Viaje del mundo. Ediciones Polifemo / Miraguano, Biblioteca de Viajeros Hispánicos. Madrid, 1993, pp. 3-478.

MALU.- Bartolomé Leonardo de Argensola: Conquista de las islas Malucas (1609). Ediciones Polifemo / Miraguano, Biblioteca de Viajeros Hispánicos, Madrid, 1992, pp. 3-354.

VALE.- Inventario y tasación de los bienes de don Fernando de Valenzuela (1677). En: Colección de documentos inéditos para la historia de España. Tomo LXVII. Madrid: 1877, pp. 137-292.

VENE.- José de Oviedo y Baños: Historia de la conquista y población de la provincia de Venezuela (1723). En: BAE, CVII: Historiadores de Indias III, Venezuela. Madrid: Atlas 1958, pp. 1-242.

RODR.- Pedro Montengón: El Rodrigo. Edición de Guillermo Carnero, 2002. Madrid: Cátedra. Colección Letras Hispánicas 522. Despojo parcial: capítulos 7 a 12.

TEA.- Benito Jerónimo Feijoo: Teatro crítico universal. Madrid: Cátedra: Letras Hispánicas. Edición de Ángel-Raimundo Fernández González (1726-1740).

POET.- Ignacio de Luzán (1737): La Poética o reglas de la poesía en general y de sus principales especies.

ITA.- Leandro Fernández de Moratín: Viaje a Italia. Desde www.cervantesvirtual.com

PEDA.- Leandro Fernández de Moratín: La derrota de los pedantes (1789). Desde www.cervantesvirtual.com

SI.- Leandro Fernández de Moratín: El sí de las niñas (1806). Desde www.cervantesvirtual.com

MARR.--José Cadalso: Cartas marruecas. Desde www.cervantesvirtual.com

ERU.- José Cadalso: Los eruditos a la violeta. Desde www.cervantesvirtual.com

SAMA1.- Félix María de Samaniego: Ensayos. Edición de Emilio Palacios Fernández. Desde www.cervantesvirtual.com

SAMA2.- Félix María de Samaniego: Epistolario. Desde www.cervantesvirtual.com

CURIO.- Ramón de Mesonero Romanos: Obras jocosas y satíricas de El Curioso Parlante. Desde www.cervantesvirtual.com

ENR.- Mariano José de Larra: El doncel de don Enrique el Doliente. Desde www.cervantesvirtual.com

TRAF.- Benito Pérez Galdós: Trafalgar. Desde www.cervantesvirtual.com

EMPE.- Benito Pérez Galdós: Juan Martín el Empecinado. Desde www.cervantesvirtual.com

FON.- Benito Pérez Galdós: La Fontana de Oro. Desde www.cervantesvirtual.com

PERF.- Benito Pérez Galdós: Doña Perfecta. Desde www.cervantesvirtual.com

LEON.- Benito Pérez Galdós: La Familia de León Roch. Desde www.cervantesvirtual.com 
DESH.- Benito Pérez Galdós: La desheredada. Desde www.cervantesvirtual.com FORT.- Benito Pérez Galdós: Fortunata y Jacinta. Desde www.cervantesvirtual.com

NAZ.- Benito Pérez Galdós: Nazarín. Desde www.cervantesvirtual.com

REGE.- Leopoldo Alas Clarín: La Regenta. Desde www.cervantesvirtual.com

PEÑ.- José María Pereda: Peñas arriba. Desde www.cervantesvirtual.com

LIRI.- Emilia Pardo Bazán: El lirismo en la poesía francesa. Desde www.cervantesvirtual.com

PALP.- Emilia Pardo Bazán: La cuestión palpitante. Desde www.cervantesvirtual.com

PAZO.- Emilia Pardo Bazán (1852-1921): Los pazos de Ulloa (1886). Desde www.cervantesvirtual.com

Bibliografía

Alcina Franch, Juan / Blecua, José Manuel (1975): Gramática española. Barcelona: Ariel.

Barra Jover, Mario (2007): „Cambios en la arquitectura de la prosa española y romance: sintaxis y cohesión discursiva por correferencia nominal", en: Revista de Filología Española LXXXVII / 1, 7-43.

(2008): „Tradición discursiva, creación y difusión de innovaciones sintácticas: la cohesión de los argumentos nominales a partir del siglo XIII", en: J. Kabatek (ed.): Sintaxis histórica del español. Nuevas perspectivas desde las tradiciones discursivas Madrid / Frankfurt: Vervuert / Iberoamericana, .

Bassols de Climent, Mariano (1956): Sintaxis latina. Madrid: CSIC, Textos Universitarios.

Bello, Andrés (1859): Gramática de la lengua castellana: destinada al uso de los americanos. En: J. J. Gómez Asencio (2001): Antiguas gramáticas del castellano. Colección Clásicos Tavera, Serie VIII: „Lingüística y antecedentes literarios de la Península Ibérica". Mapfre-Fundación Histórica Tavera.

Blatt, Franz (1957): „Latin Influence on European Syntax”, en: Classica et mediaevalia 18, 133-178.

Borreguero Zuloaga, Margarita / Álvaro S.Octavio de Toledo (2006): „La crónica de sucesos (ss. XVII - XIX). Evolución y desarrollo de la organización informativa textual", en: Actas del VI Congreso Internacional de Historia de la Lengua Española, Madrid: Arco/Libros, 2653-2667.

(en prensa): „Presencia y función de los encapsuladores en las crónicas periodísticas del s. XVII", en: Philologia Hispalensis.

Brown, Gillian; George Yule (1993): Análisis del discurso. Madrid: Visor.

Brucart, José $M^{\text {a }}$ (1999): „La estructura del sintagma nominal: las oraciones de relativo", en: I. Bosque / V. Demonte (dirs): Gramática descriptiva de la lengua española. Madrid: Espasa-Calpe, 395-522.

Cuervo, Rufino J. (1886 y ss): Diccionario de construcción y régimen de la lengua castellana. Herder (edición actualizada en cederrón). 
Eberenz, Rolf (2000): El español en el otoño de la Edad Media. Sobre el artículo y los pronombres. Madrid: Gredos.

Elvira, Javier (1985): "Qual con antecedente en español antiguo”, en: Revista de Filología Española 65, 305-316.

Esparza Torres, Miguel Ángel (2006): „Pautas para el análisis de la cohesión y la coherencia en textos españoles", en: RILCE 22.1, 59-89.

Fernández Ramírez, Salvador (1951): Gramática española, I. Los sonidos, el nombre y el pronombre. Madrid: Revista de Occidente. Reedición en 3 vols. de J. Polo. Madrid: Arco Libros, 1986.

García García, Serafina (1990): Los transpositores oracionales en la obra histórica alfonsí. Estudio de sintaxis funcional. Oviedo: Departamento de Filología Española.

Girón Alconchel, José Luis (2003): „Evolución de la cohesión en el discurso ensayístico entre 1648 y 1726”, en: J. L. Girón, F. J. Herrero, S. Iglesias y A. Narbona (eds.), Estudios ofrecidos al profesor José Jesús de Bustos Tovar, vol. 1, Madrid: Editorial Complutense, 331-360.

Gómez Torrego, Leonardo (2002): Nuevo manual de español correcto, vol 2. Madrid: Arco / Libros.

Halliday, M.A.K.; R, Hasan (1989): Cohesion in English. Londres: Longman.

Herrero Ruiz de Loizaga, F. Javier (2005): Sintaxis histórica de la oración compuesta en español. Madrid: Gredos. Biblioteca Románica Hispánica.

Iglesias Casal, Isabel (1996): Los relativos en la prosa renacentista castellana. Oviedo: Departamento de Filología Española.

Jacob, Daniel / Kabatek, Johannes (2001): „Introducción: Lengua, texto y cambio lingüístico en la Edad Media iberrománica", en: D. Jacob / J. Kabatek (eds.): Lengua medieval y tradiciones discursivas en la Península Ibérica. Descripción gramatical, pragmática histórica, metodología. Madrid: Vervuert.

Kabatek, Johannes (2005): „Tradiciones discursivas y cambio lingüístico”, en: Lexis 29, / 2, 151-177.

Kloss, Heinz (1952/1978): Die Entwicklung neuer germanischer Kultursprachen von 1800 bis 1950. Múnich: Pohl.

(1967): „Abstand Languages and Ausbau Languages”, en: Anthropological Linguistics 9, 29-41.

Koch, Peter / Wulf Oesterreicher (1990 [2007]): Lengua hablada en la Romania: español, francés, italiano. Madrid: Gredos (Biblioteca Románica Hispánica). Trad. esp. de A. López Serena.

Lapesa, Rafael (1966) [2000]): „El artículo como antecedente de relativo en español", en: Estudios de filología e historia literaria lusohispanas e iberoamericanas publicados para celebrar el tercer lustro del Instituto de Estudios Hispánicos: La Haya: Van Goor, 287-298. Recogido en: M. T. Echenique / R. Cano (eds): Estudios de morfosintaxis histórica del español. Madrid: Gredos, $388-401$ 
Octavio de Toledo, Álvaro S. / Lola Pons Rodríguez (en prensa): „¿Mezclando dos hablas?: la imitación de la lengua medieval castellana en la novela histórica del XIX".

Pons Bordería, Salvador (2008): „Gramaticalización por tradiciones discursivas: el caso de esto es", en: J. Kabatek (ed.): Sintaxis histórica del español. Nuevas perspectivas desde las tradiciones discursivas. Madrid / Frankfurt: Vervuert / Iberoamericana, 249-274

Pons Rodríguez, Lola (2001-2002): „La historia de en cuanto a como tematizador", en: Anuari de Filologia 2001-2002, no 11-12 (aparecido en 2006), 73-94.

(2006a): „Sobre quanto limitativo en español preclásico”, en: J. J. Bustos Tovar / J. L. Girón (eds.): Actas del VI Congreso Internacional de Historia de la Lengua Española. Madrid, 29 de septiembre - 3 de octubre de 2003. Madrid: Arco/Libros, vol. I, 1019-1034.

(2006b): „Una reflexión sobre el cambio lingüístico en el siglo XV", en: Actas del $V$ Congreso Andaluz de Lingüística General. Homenaje a J. A. de Molina Redondo. Granada: Granada Lingvistica-Serie Collectae, 2006, Tomo III, 1563-1577.

Real Academia Española (1973): Esbozo de una nueva gramática de la lengua castellana. Madrid: Espasa Calpe.

Real Academia Española / Asociación de Academias de la Lengua Española (2005): Diccionario panhispánico de dudas. Madrid: Santillana Ediciones Generales SL.

\footnotetext{
${ }^{1}$ Aunque la calificación de estas oraciones como yuxtapuestas no ha sido completamente aceptada y las clasificaciones que se hacen de este uso son muy dispares. Fernández Ramírez (1951: 246) resume el valor sintáctico-discursivo de este empleo de el cual, señalando un valor "demostrativo conectivo". Alcina / Blecua (1975: 554) hablan de aposición oracional para estos usos de lo cual y lo que en español actual. García García (1990: 70 passim) rechaza la equivalencia entre el cual y demostrativo: los demostrativos pueden aparecer sin anáfora contextual y no establecen relación sintáctica con la oración anterior, aunque reconoce que hay ocasiones en que el cual es un "grupo sintagmático" (=idemostrativo?). No está clara la postura de Iglesias Casal (1996: 160), quien primero rechaza la idea de García García de que el cual siempre tenga antecedente y le quita suficiencia a la razón de que no aparecen conectores previos a el cual; pero, después (pág. 166) reconoce que hay diferencias entre este relativo y el demostrativo. Brucart (1999: 424), por último, aduce como contraargumento para su consideración como oración principal la carencia de libertad de estas oraciones, que precisan de un antecedente en la oración anterior y añade: „la rígida colocación del pronombre relativo que las encabeza y la necesidad de adyacencia lineal con el antecedente llevan a pensar que se trata de oraciones subordinadas", y reconoce, en fin, su proximidad a las oraciones principales por su conmutabilidad con demostrativo (las llama relativas yuxtapuestas paratácticas). Como afirma este autor, la consideración subordinada o no de estas oraciones dependerá en gran medida de lo que entendamos por subordinación. Sólo un factor aparta a estas oraciones de ser entendidas en todos los aspectos como equiparables a oraciones principales, y es la incapacidad que muestran para anteponer al relativo un conector.

${ }^{2}$ No parece casual que el ejemplo que Brucart (1999: 421) adjunta de relativa yuxtapuesta -lo que él llama „yuxtaposición paratáctica”- contenga el marcador digresivo por cierto: „También faltó a la reunión Luis. Al cual, por cierto, le han impuesto una fuerte multa por ello".

${ }^{3}$ En la ejemplificación que se cite de ahora en adelante, se marcarán en cursiva la estructura de el cual con antecedente en forma de adjunto asociado y su antecedente; se utilizarán para la citación de la fuente de los ejemplos las claves que se ha asignado a cada obra (vid. Corpus, al final).
} 
${ }^{4}$ Esta separación parte de la distinción de cuatro clases de cohesión que separaron Halliday / Hasan (1989): cohesión por referencia (elementos pronominales); cohesión por sustitución con proformas; cohesión por elipsis y cohesión léxica.

${ }^{5}$ Hay obras de corta magnitud como el Arte cisoria de Villena, Del uso y exercicio de la retórica de Céspedes o La derrota de los pedantes, de Moratín, que son contrapesadas por textos de extensión más dilatada como las Siete Partidas, la Crónica del Halconero, los Diálogos de amor de León Hebreo o Fortunata y Jacinta, por nombrar algunos.

${ }^{6}$ Para el concepto de tradición discursiva como „molde histórico-normativo, socialmente establecido, que se respeta en la producción del discurso" vid. Kabatek (2005).

${ }^{7}$ Otros elementos pueden insertarse entre el relativo y su antecedente adjunto: numerales cardinales, muy raramente ordinales: „En Turquía todos son esclabos, sino sólo el Gran Turco, y d'éstos, tres más privados haze vaxás, que como dicho tengo es dignidad de por vida, los quales tres vaxás son los mayores señores que allá hai" (TURQ: 687). El elemento introducido puede ser también un adjetivo que se antepone al sustantivo que modifica; ello sólo ocurre a partir del siglo XV y en pocas ocasiones (11 muestras dentro de todo el corpus): „,e en el otro joyel estava guarnecida una virtuosa piedra toda de letras maravillosamente scriptas e entalladas de suso la misma piedra, non fechas parecidas por artefiçio de home vivo, en que dezían [...], la qual preciosa piedra se dezía ser una de las con que el sancto [...] fue apedreado" (PASO: 142). También, el cuantificador todo puede preceder al relativo, aunque es muy inusual: „Do ademas de lo dicho, todo el derecho que yo he e me perteneze en las iglesias de los lugares de Alixa e de Pobladura de Valderia e de la Nora. Todas las quales cosas de oy dia en adelante de mio jure e de mio poder sean salidas e en vuestro poder sean entradas" (NOG13: 126).

${ }_{8}^{8}$ Propiamente, hablar de copia o de cuasi-copia impone de entrada un modelo de procesamiento discursivo en que no se tiene en cuenta que desde que se menciona al antecedente hasta que se recupera puede haberse incorporado información que ha hecho cambiar el referente original, esto es: que el antecedente recuperado por el adjunto, ni siquiera cuando se copia literalmente, coincide en sus rasgos con el que se mencionó en su primera introducción en el discurso. El decurso puede implicar cambio en el estado del referente original, acumulación de propiedades, alteraciones que ya están asociadas al antecedente cuando este se convierte en adjunto. En el siguiente ejemplo: „Assi son los pulmones, que siguen al coraçon y le siruen en su continuo mouimiento, los quales pulmones, siendo espongiosos, se estienden y se recojen (DIAL: 323); se mantiene la identidad referencial entre antecedente y adjunto, ya que aquél no ha cambiado sus propiedades desde que ha sido enunciado hasta que ha sido retomado, pero no en este otro, donde la sala primeramente nombrada es un referente con atributos distintos cuando se retoma: "Fizieron una sala de madera bien ordenada e fecha de verjas, en la qual sala de luengo avía trenta passos e de ancho avía diez passos muy compassados, e todas con paños franceses ricamente emparamentada e cubierta por ençima, de la qual sala fizieron dos mesas de madera a buena ordenança" (PASO: 105).

${ }^{9}$ Más complejo es el ejemplo que sigue, donde se retoma como antecedente de manera literal a un sustantivo caso que aparece como antecedente integrado en la locución condicional caso que; en este caso estamos ante una repetición etimológica que no es tal si consideramos el proceso de gramaticalización por el que estaba pasando la forma en caso que en el siglo XIV: „E caso que por siniestras ynformaçiones e consejos de las personas, la yntençión del Rey de Castilla no sea conforme a la de los rreyes de Aragón e de Nauarra, ni sea tal como cunple a guardar e bien conseruar los debdos e amoríos todos, todo será muy desplaziente a los rreyes de Aragón e de Nauarra, e por su poder desbiarán toda rrotura e escándalo, e nunca ellos vernán sino forçados. En el qual caso sea la culpa e caso del Rey de Castilla, o más propiamente de las dichas personas de siniestra yntençión" (VISIO: 65).

${ }^{10}$ Se documentan también los conocidos cruces cognitivos entre ambas nociones: „Con todo eso se detuvieron como media hora, al cabo del cual espacio volvieron a recoger la soga con mucha facilidad" (QUIJ: II.22).

${ }^{11}$ Este ejemplo testimonia un uso funcionalmente doble de la construcción con qual y antecedente muy propio de Cervantes, a quien pertenece también este ejemplo: „Llegose a él Erastro y, trabándole recio del brazo, le hizo volver en sí, aunque tan desacordado que parecía que de un pesado sueño recordaba, las cuales muestras de dolor no pequeño le causaron a los que le veían, y luego Erastro le dijo" (GALA: 85r).

${ }_{12}$ Coincidimos con la definición de encapsulador que aportan Borreguero / Octavio de Toledo (en prensa): un elemento con referencia anafórica que se integra en un sintagma definido, con capacidad para condensar informativamente el fragmento discursivo al que se refiere, prototípicamente en posición temática y en general aludiendo a un predicado de naturaleza eventiva. 
${ }^{13}$ Corpus de Referencia Diacrónico del Español [http://www.rae.es]. Última consulta: octubre de 2007. De los 70 ejemplos obtenidos resto 16, ya que se ofrece dos versiones (por tanto, con doble relación de ejemplos) de los Castigos de Sancho IV.

${ }^{14}$ El concepto de Ausbau o elaboración de Heinz Kloss explica la gestación de una lengua de cultura como un proceso de generalización de escenarios comunicativos en que virtualmente se puede emplear esa lengua, con el desarrollo, en consecuencia, de géneros textuales o tradiciones discursivas que sean necesarias. Dentro de la división de Kloss pueden separarse dos tipos de elaboración paralelas: la extensional y la intensional, según Koch / Oesterreicher, 1990 [2007]). La elaboración extensional es la apropiación gradual de tradiciones discursivas propias de la distancia comunicativa; a la elaboración intensional corresponden otros procesos, por ejemplo, el desarrollo de conectores, desarrollo de la estructura informativa de la frase, intensificación en la producción de sustantivos abstractos, etc.

${ }^{15}$ En Pons Rodríguez (2006b) está ese esquema sobre las dos dimensiones en que se pueden dar innovaciones y sus fundamentos causales: innovaciones por elaboración (cambios desde arriba) o innovaciones por expresividad (cambios desde abajo). Ilustro estas cuestiones en dicho trabajo con los cambios lingüísticos que vivió el español cuatrocentista.

${ }^{16}$ Como también habría vinculación con otras formas de envío fórico, así las estructuradas en torno a tal (la tal casa etc), sobre las que me ocuparé en otra ocasión. 